\title{
Ethics Teaching in Education for Sustainable Development
}

\author{
By Lars Samuelsson ${ }^{*} \&$ Niclas Lindström ${ }^{ \pm}$
}

\begin{abstract}
Education for sustainable development (ESD) is nowadays internationally considered an important aspect of the overall education of children and young people in the world. It is included among the goals of the UN 2030 Agenda for Sustainable Development. Besides its content - sustainable development - ESD is also characterized by its emphasis on a democratic and participatory educational procedure. In this paper, we show how both these aspects of ESD its content and procedure - reveal the importance of bringing ethical considerations into ESD, as well as provide challenges for ethics teaching in ESD.
\end{abstract}

Keywords: education for sustainable development (ESD), sustainable development, ethics education, teaching ethics, participatory education, controversial issues

\section{Introduction}

Education for sustainable development (ESD) is nowadays internationally considered an important aspect of the overall education of children and young people in the world (e.g., UNESCO, 2019a). It is included among the goals of the UN 2030 Agenda for Sustainable Development (United Nations, 2019; see in particular target 4.7). Besides its content - sustainable development - ESD is also characterized by its emphasis on a democratic and participatory educational procedure: "Designing teaching and learning in an interactive, learner-centred way that enables exploratory, action oriented and transformative learning" (UNESCO, 2019b).

The object of ESD, the idea of sustainable development, is both normative and imprecise. It is normative because it is generally presupposed that sustainable development is something that we ought to strive for. The statement that something is sustainable in the sense intended by those who appeal to this idea is not merely descriptive, but also normative. What is sustainable is also, in that respect, good. If it were not for this normative presupposition, it is hard to see why people would take an interest in sustainable development, and it would not have the prominent role that it has within, e.g., politics, policy and education. Hence, the 'for' in "education for sustainable development". Such education is not merely about sustainable development; it is intended to further such development.

The idea of sustainable development is imprecise because the different concepts that together constitute the idea can all be given different interpretations, generating conflicting sustainability goals (e.g., Dobson, 1998, Ch. 2). This point

*Associate Professor, Umeå University, Sweden.

${ }^{ \pm}$Associate Professor, Umeå University, Sweden. 
is developed in the next section. Thus, it is a controversial issue precisely what is to count as sustainable development (e.g., Lélé, 1991; Beckerman, 1994; Dobson, 1998, Ch. 2; Jacobs, 1999; O’Neill, 2001; Stradling, 1985; Oulton, Day, Dillon, \& Grace, 2004). This, in turn, means that education for sustainable development cannot be neutral (even if education about sustainable development perhaps can). Instead, it is bound to rest on implicit or explicit ethical assumptions. It is therefore an important component within a comprehensive ESD to reveal and discuss such assumptions.

Despite the fact that ethical issues are at the very core of ESD, there is a considerable risk that its ethical dimension is not treated in such education, or that it is treated very sparsely. One reason for this is simply tradition. Sustainability research and discussion has so far largely taken place within the framework of the natural and social sciences. Accordingly, the development of ESD has mostly drawn on input from these sciences. Thus, teachers involved in ESD do not typically have a background in ethics, and hence cannot generally be expected to be well-versed in ethical theory.

\section{Purpose}

This paper highlights the need for ethical reflection in ESD. Its main purpose is to show how the two aspects of ESD mentioned above - its content and procedure - reveal the importance of bringing ethical considerations into ESD, as well as provide challenges for ethics teaching in ESD. However, we will also briefly sketch what we take to be a promising suggestion of a way to deal with these challenges.

\section{Method and Research Material}

The character of the paper is that of a broadly philosophical discussion paper. It builds on an analysis of the concept of education for sustainable development (ESD) ${ }^{1}$. Hence the method used is primarily the analytic approach that is characteristic of modern analytic philosophy, with conceptual analysis and examination of arguments. The research material used is regulatory documents and relevant reports.

\section{Outline}

In the next section we put the focus on the idea of sustainable development i.e., the content of ESD - and the ethical issues that it raises. The subsequent section deals with the procedure of ESD and the boundaries it sets for how the ethical dimension of sustainable development should be treated within the

\footnotetext{
${ }^{1}$ While there has been some discussion about the ethical dimension of ESD (e.g., Öhman, 2008; Franck \& Osbeck, 2017; Van Poeck, Östman, \& Öhman, 2019), it has not been built on an analysis of the concept of ESD - including the concept of sustainable development - and thus not detailed the multifaceted complexity of this dimension. We take the latter to be an important task for exposing the challenges that ESD-teachers face in relation to the ethical dimension of ESD.
} 
framework of ESD. These two sections together provide background to the particular challenges to ethics teaching in ESD that we develop and discuss in the section that follows.

\section{The Content of Education for Sustainable Development}

While there are numerous characterizations of sustainable development in the literature, the so called Brundtland-definition, found in The Brundtland Report, is undoubtedly the one that has had the greatest impact, politically as well as within ESD (World Commission on Environment and Development, 1987) ${ }^{2}$. Our account of the ethical aspects of sustainable development that follows is built on that characterization $^{3}$. As stated in The Brundtland report, sustainable development is:

development that meets the needs of the present without compromising the ability of future generations to meet their own needs ${ }^{4}$ (World Commission on Environment and Development, 1987, Ch. 2, §1).

Now, at least the following concepts from this characterization can be problematized from an ethical point of view: development, needs, the present, compromising, ability and future generations. We will go through them one by one in order to reveal the multifaceted and complex ethical dimension of the idea of sustainable development. An important upshot of this exposition is the insight that depending on how one interprets these concepts, different sustainability goals emerge - more or less demanding.

Furthermore, how to interpret these concepts is largely a matter of ethical considerations (broadly conceived, comprising also fundamental political considerations). As we will see, there are several ethical questions that need to be answered in order to specify the different concepts that together make up the sustainability idea. Our purpose here is not to come up with any answers to these questions. As explained in the introduction, our main aim is to reveal the need for ethical considerations within ESD and the challenges that ethics teaching in ESD

\footnotetext{
${ }^{2}$ This characterization is found in the UN report Our Common Future, popularly referred to as The Brundtland Report, after the former prime minister of Norway, Gro Harlem Brundtland, who chaired the commission (World Commission on Environment and Development, 1987).

${ }^{3}$ Note that our main point in the coming discussion is that the idea of sustainable development is imprecise and normatively saturated. The fact that there are numerous other characterizations of sustainable development in the literature only serves to strengthen this point. However, note also that even though there exist numerous competing characterizations of sustainability, the ones that are relevant to our discussion are all bound to share certain core elements (roughly, some versions of the elements that we will go through in this section). Hence, with little alteration, our presentation and discussion should work for these other characterizations as well.

${ }^{4}$ Although this characterization has defined the modern discussion about sustainable development, related ideas had been expressed long before the publication of The Brundtland Report (see, e.g., Du Pisini, 2006, for a historical account of the sustainability idea). Our purpose in this paper, however, is to reveal and discuss the ethical dimension of sustainable development and ESD as these ideas are currently understood, originating from The Brundtland Report.
} 
faces. What our account shows, we submit, is precisely the need for such considerations.

\section{Development}

How is the concept of development supposed to be understood in the present context? In The Brundtland Report, it is clear that this concept is closely related to that of economic growth (World Commission on Environment and Development, 1987, Ch. 2). At the same time, many people - in particular within the green movement, broadly conceived - take the pursuit of economic growth to be one of the main roots of the environmental problems that motivated the search for a more environmentally friendly way of life to start with. ${ }^{5}$ Hence, depending on its interpretation, already the concept of development makes the goal of sustainable development controversial.

One way out of this controversy is to drop the concept of development and simply talk about sustainability in various contexts (e.g., sustainable forestry, sustainable agriculture, sustainable use of natural resources, sustainable cities, sustainable schools, etc.). Another possibility is to argue for some particular interpretation of development as being compatible with the other parts of the sustainability idea. In any case, there are normative questions of a fundamental political nature involved in arriving at a view about whether economic growth, or some other notion of societal development, is desirable. ${ }^{6}$

\section{Needs}

What should count as a need in the present context? The needs referred to in the Brundtland-characterization of sustainable development are clearly basic needs, in some sense: "in particular the essential needs of the world's poor, to which overriding priority should be given" (World Commission on Environment and Development, 1987, Ch. 2, §1). However, even if we agree that the needs relevant to the goal of sustainable development are basic needs, there is room for different views about what it means that people's needs are satisfied. Even the notion of basic needs can be given more or less demanding interpretations.

One may also take issue with the Brundtland-conception of needs and argue for a stronger sustainability goal according to which we should be required to safeguard not only basic needs of the present and the future, but also needs in some wider sense ${ }^{7}$. For instance, perhaps people have needs to stand in certain relations to other people (e.g., friendships relations). Some might further argue that we also have needs to stand in certain relations to nature, or to some non-human

\footnotetext{
${ }^{5}$ See for instance O'Neill (2001, p. xiii). For recent research supporting the view that economic growth is difficult to reconcile with sustainability, see Parrique et al., (2019), Hickel and Kallis (2019).

${ }^{6}$ While leaving open the question about in which senses development may be compatible with sustainability, we sometimes write in terms of sustainability instead of sustainable development for ease of exposition.

${ }^{7}$ For an overview of relevant philosophical discussions about needs and their purported importance, see Brock and Miller (2019).
} 
entities. Depending on how we interpret needs in the characterization of sustainable development, we will arrive at more or less demanding sustainability goals.

\section{The Present}

The reference to the present stresses the question about to whom development should be sustainable. If we again look to The Brundtland Report, the answer is pretty clear. Sustainable development is focused on human beings, and the satisfaction of human needs. That is to say, it is strictly anthropocentric. However, such an anthropocentric restriction is not uncontroversial. Most people today take at least some needs of sentient non-human creatures to be morally significant. Should not these needs also be accounted for in the goal of sustainable development? Within environmental ethics the critique goes further, since many environmental ethicists ascribe direct moral importance even to non-sentient nature, such as non-sentient organisms, species, ecosystems or the biosphere as a whole. ${ }^{8}$ Generally, the more entities we include as comprised by the sustainability goal, the more demanding is the goal.

One way to deal with this challenge could be to insist that the goal of sustainable development should be anthropocentric, but open for the need for other, complementing, non-anthropocentric goals (taking into account, e.g., the interests of sentient non-human creatures or the flourishing of ecosystems). Another possibility is to widen the scope of the sustainability goal to also include the needs of some non-human entities. In any case, it is a fundamental ethical question which entities in the world are directly morally important, and what the moral significance of their moral importance is. Depending on how we answer such questions, we will either end up with more or less demanding sustainability goals or with different views about the role of the sustainability goal among other ethical goals.

\section{Compromising}

What does it take to compromise the ability of people to meet their own needs? Here there is a range of possible views that one could take. One issue that needs to be attended to is that of risks. Are we compromising the need-meeting ability of future people more if we expose them to larger risks of not having their needs satisfied (irrespective of whether their needs will in fact be satisfied)? Take nuclear power as an example. Putting the serious problems related to uranium mining to one side, some people consider nuclear power a particularly sustainable energy source, given the low level of greenhouse gas emissions involved. On the other hand, if something goes wrong in the process of generating nuclear energy or with the storing of nuclear waste, the outcome in terms of satisfaction of people's needs may be disastrous. In that respect, the risks involved are severe. This fact

\footnotetext{
${ }^{8}$ See, e.g., O'Neill (2001, pp. xxi-xxv). For a short presentation of a version of this critique, see Leist and Holland (2000, pp. 6-7).
} 
makes some people consider nuclear power a particularly unsustainable energy source.

\section{Ability}

What is required for people to have the ability to satisfy their own needs? This is one of the most widely discussed questions in the literature on how to interpret the sustainability goal. Simplified, the main dividing line in the debate goes between two forms of "capital" that one may consider essential to this goal. Depending on which of these two forms of capital one puts the focus on, two different main versions of the sustainability goal emerge, one weak version and one strong version. In the words of John O'Neill (2001, p. xxxi), these respective versions state:

1. [weak sustainability] that overall capital - the total comprising both natural and manmade capital - should not decline, or

2. [strong sustainability] that natural capital in particular should not decline. [---]

"Weak sustainability assumes that manmade and natural capital are basically substitutes".

"Strong sustainability assumes that manmade and natural capital are basically complements".

Arguably, strong sustainability is much more demanding than weak sustainability. Strong sustainability implies that we have a moral obligation to preserve certain natural resources per se. Weak sustainability, on the other hand, is often understood to simply provide us with the obligation to maintain economic growth, albeit within the boundaries set by the other parts of the sustainability goal (compare with the above discussion about the notion of development).

\section{Future Generations}

First, we may note that the reference to future generations again stresses the question about to whom development should be sustainable; should only human beings be in included in these future generations? But it also stresses the complicated ethical issue of how to account for our ethical obligations with respect to people and other beings who do not live yet (whose identities are typically yet to be decided, partly by the actions undertaken by people who live now). This issue is far too complex to start to unfold here; suffice it to say that it has turned out to be one of the trickiest issues within modern normative ethics (see e.g., Meyer, 2016; O'Neill, 2001, pp. xvi-xxi). Depending on how one deals with this issue, different sustainability goals will be generated.

\section{Implementing the Goal}

Besides the questions about how to interpret the sustainability goal, there are further ethical questions that need to be attended to regarding the implementation 
of the goal. Suppose that we would all agree on a precise definition of "sustainable development", one in which all the included concepts were specified down to a level such that no controversy remained regarding what a sustainable development would amount to. Even so, there would still be room for extensive ethical disagreement concerning how to reach the goal of sustainable development, and about its significance as compared to other potential goals.

(1) To start with, one may have different views about which actions and policies that would be required to reach sustainable development. We may agree on a goal without agreeing on how to best reach it.

(2) Even if we would agree on how to best reach the sustainability goal, we could still disagree on how the responsibility for undertaking the required actions and policies should be shared. For instance, some believe that the main responsibility lies with collectives, such as states, while others think it lies with individuals, e.g., through their consumption choices.

(3) Somewhat related to the question about responsibility, there is the tricky issue of how to "boil down" the global general sustainability goal to local action. We hear talk about, e.g., sustainable lifestyles, sustainable consumption, sustainable companies, and sustainable schools. How do these local instances of sustainability relate to the general global sustainability goal, if they relate to it at all, and how should they relate to it? These are important questions for all those who through their actions and behavior want to make a difference with respect to sustainability. Not the least, it is important in relation to ESD, which emphasizes local participation and action. On a very concrete level, one may want to ask what one's school or one's class can and should do for a more sustainable development.

(4) The sustainability goal is arguably not the only goal that needs to be attended to in political or individual decision-making. We have already noticed that it may have to be complemented with other environmental goals taking certain non-human entities into consideration. But there may also be other kinds of goals relating to other important values or ideals - that individuals and politics should be concerned with besides the sustainability goal ${ }^{9}$. Such other goals may come in conflict with the sustainability goal, revealing the need to find ways to weigh this goal against such other goals. How important is sustainable development as compared to other important values or ideals?

\section{The Need for Ethical Reflection}

As stated above, our purpose here is not to come up with any answers to the questions that we have posed in this section. As explained in the introduction, our aim is to reveal the need for ethical reflection in ESD. Depending on how one answers the various questions that we have raised, one will arrive at different

\footnotetext{
${ }^{9}$ To what extent there are such other goals depends on how much of our moral and political values and ideals that are comprised by the sustainability goal. Some want to include very much, so that for instance democracy, equality and political rights are all comprised by it. But even so, there are arguably aspects of these issues that will not be accounted for by reference to the goal of sustainability. In any case, there are certainly moral reasons that individuals should take into account in their personal moral reasoning that are not comprised by the sustainability goal.
} 
sustainability goals, more or less demanding. Which answers one gives to these questions will in turn at least partly depend on one's ethical views (in a wide sense, including also fundamental political views). This means that education for sustainable development cannot be neutral. Instead, it rests on implicit or explicit ethical assumptions. Thus, a comprehensive and reflective ESD requires that one reveals and discusses such assumptions.

However, as the concept of ESD is understood in the literature, there are boundaries for how ethical considerations should be treated within the framework of ESD. Inherent in the very concept of ESD is a presupposition that such education should be carried out by way of a certain kind of educational procedure. ${ }^{10}$ It is to this procedural aspect of ESD that we now turn our attention.

\section{The Procedure of Education for Sustainable Development}

There is widespread agreement among those who work practically or theoretically with ESD that such education should be conducted by way of a student-active, learner-centered, interactive form of educational procedure that promotes democratic participation. It even seems accurate to say that as the term 'education for sustainable development' has come to be used, the application of such a teaching procedure lies in its very meaning. This is apparent in UNESCO's description of what ESD amounts to, where one of the items is pedagogy and learning environment: "Designing teaching and learning in an interactive, learnercentred way that enables exploratory, action oriented and transformative learning" (UNESCO, 2019b; see also UNESCO, 2017).

One plausible explanation of why this kind of educational procedure has come to be seen as a component of ESD is that sustainability, as the term is commonly used, does not only have an ecological dimension. In the wake of The Brundtland Report, it has become standard to talk about three interrelated dimensions of sustainability: ecological, social and economic. Within the social dimension, participation and democratic governance are considered central prerequisites for a sustainable development.

In light of this procedural aspect of ESD, the approach to ethics teaching in ESD should be such that it is suitable for, or forms an integral part of, the kind of educational procedure briefly outlined above. Consider the following learning objectives for ESD stated by UNESCO:

Normative competency: the abilities to understand and reflect on the norms and values that underlie one's actions; and to negotiate sustainability values, principles, goals, and targets, in a context of conflicts of interests and trade-offs, uncertain knowledge and contradictions.

\footnotetext{
${ }^{10}$ One may of course question that presupposition, but that is an issue which lies outside the scope of this paper.
} 
Critical thinking competency: the ability to question norms, practices and opinions; to reflect on own one's [sic] values, perceptions and actions; and to take a position in the sustainability discourse (UNESCO, 2017, p. 10).

In line with these learning objectives, the kinds of democratic and participatory approaches to education that are assumed within ESD seem well suited for the task of revealing and discussing ethical assumptions. However, this requires that an appropriate approach to ethics education is incorporated within ESD. At this point, two potential problems appear: (1) the most common way of teaching ethics - a theory-based approach - seems ill suited for this task; (2) in the context of ESD we need an approach to ethics education that is available also to teachers who are not so well experienced within the field of ethics (since many teachers involved in ESD arguably belong to this group). Thus, the challenge we are faced with is to find ways of dealing with (1) and (2). Let us look at this challenge in some more detail.

\section{The Challenge}

We are now in a position to illustrate the multifaceted ethical complexity of $\mathrm{ESD}$, bringing in both the aspects pertaining to its content and those pertaining to its procedure (Figure 1).

Figure 1. The Ethical Branches of ESD

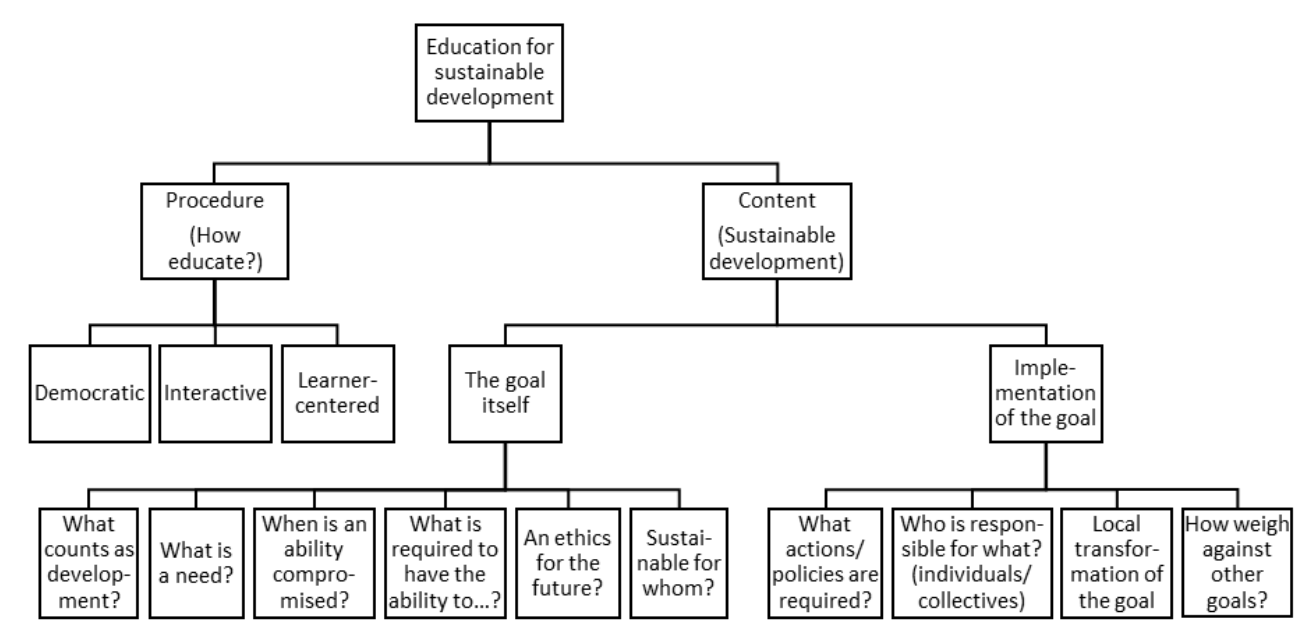

Source: Original.

This reverse tree figure illustrates the various ethical issues that arise in connection with ESD, as branches emanating from that concept ${ }^{11}$. The issues pertaining to the content of ESD - sustainable development - are expressed as questions, where each question has an ethical dimension. How one wants to

\footnotetext{
${ }^{11}$ And it is not intended to be exhaustive. There may be additional ethical issues to those we have presented in this paper.
} 
answer these questions depends on one's ethical views. As explained in the above section about the content of ESD, different answers to these questions will generate different sustainability goals, more or less demanding. The issues pertaining to the educational procedure of ESD are expressed as central terms ('democratic', 'interactive', 'learner-centered') intended to capture the democratic and participatory character presupposed within the framework of ESD. The question of how to educate for sustainable development needs to be asked by teachers and others involved in ESD.

The upshot of our discussion so far is not that teachers of ESD should bring up all the ethical aspects of sustainable development in their teaching. To do so might be both impossible and inappropriate. ESD is supposed to permeate the schooling of children and adolescents from an early age. It would for instance be preposterous to bring up difficult philosophical issues about our obligations regarding future generations with pre-school children. Hence this is not the challenge we want to discuss.

The idea, rather, is that teachers involved in ESD should be aware of the multifaceted ethical complexity of sustainable development, and of the fact that any specification of a general characterization of sustainable development (e.g., the Brundtland-characterization) is bound to be controversial - and that teaching proceeding from any such specification is non-neutral. It is important both that teachers have this awareness and that they have the ability to critically reflect on the ethical dimension of sustainable development, so that they can pass this awareness on to their pupils in their mutual work with sustainability issues in school. ${ }^{12}$ Furthermore, to the extent that teachers want to abide by the spirit of ESD, this should be done within a democratic and participatory teaching framework.

The challenge, then, is to find an approach to ethics teaching in ESD that is (1) suitable with respect to both its content and its educational procedure, and (2) available also to teachers who are not experienced within the field of ethics.

Managing the ethical dimension of sustainable development in a teaching context is a major challenge for several reasons: Just as it is a controversial question what should count as sustainable development, it is a controversial question which ethical point of view or perspective that should guide our pursuit of such development; teachers involved in ESD are typically not very experienced within the field of ethics; and schools are expected to work with sustainability issues through all stages, with very different target groups.

These challenges all point in a direction away from the theory-based model of ethics teaching that is most common in various educational contexts. Characteristic of this model is that the pupils or students are presented with a set of very simplified versions of ethical theories, such as consequentialism (or some version

\footnotetext{
${ }^{12}$ Such a critical awareness may also serve as a guard against ESD becoming a kind of indoctrination, and against accusations of indoctrination. There is always a risk, when teaching with the purpose of promoting a normative goal, that such teaching becomes - or is accused of being - a form of indoctrination (see, e.g., Hand, 2018; Samuelsson \& Lindström, 2020). Using appropriate teaching tools for critical thinking may be an efficient way to avoid this risk (e.g., Oulton, Day, Dillon, \& Grace, 2004, pp. 505-506).
} 
of it, typically utilitarianism), duty ethics (in some version), rights ethics, and virtue ethics. These simplified versions of the theories are then applied to some situations or questions. We have previously argued against using this approach to ethics teaching in certain educational contexts, especially when students read ethics outside the subject of philosophy (Samuelsson \& Lindström, 2017; Samuelsson \& Lindström, 2020) - similar criticisms have been offered by other authors, not least Davis (e.g., 2011; 2014) in the context of professional ethics. We direct the reader to these texts for a more detailed account, but in short, the most important criticism of the theory-based approach to ethics education is that it has very limited practical relevance:

In the theory-based approach, the pupils or students are introduced to a "smorgasbord" of different ethical theories. However, there is rarely enough time within the kind of courses (outside philosophy) in which ethics is treated to provide the pupils or students with the necessary resources to evaluate the reasonableness of these theories or learn to apply them adequately. In fact, that would require the pupils/students to become experts in the field of ethics. Instead, ethics appears to be a matter of simply picking or discarding the mutually incompatible theories on this smorgasbord without any clear reasons for one's choices (for this reason, we have previously referred to this model as the "smorgasbord approach" to ethics teaching; Samuelsson \& Lindström, 2017). Consequently, it remains unclear why any particular theory should be used in order to make ethical judgements, for instance in relation to sustainability issues. The practical relevance of such a smorgasbord approach is hence limited, to say the least, especially if it is applied by teachers who are not well-versed in ethical theory. And it is probably not at all relevant in ethics teaching for younger pupils. If the smorgasbord approach is the only model of ethics teaching known to an ESD-teacher (if any), there is an obvious risk that the ethical aspects of sustainable development are treated rather rigidly, to the extent they are explicitly addressed at all.

Furthermore, the theory-based smorgasbord approach to ethics education fits badly with the educational ideals inherent in ESD, which emphasizes participation through a learner-centered interactive educational setting. The theory-based approach typically involves trying to figure out what verdicts different ethical theories give when applied to various situations. This may be appropriate if the purpose of the education is to understand these ethical theories. However, that is arguably not a purpose of ESD, and it does not invite the kind of reflection required to actively participate in debates about sustainability, as for instance expressed through UNESCO's learning objectives for ESD (introduced above):

... to negotiate sustainability values, principles, goals, and targets, in a context of conflicts of interests and trade-offs, uncertain knowledge and contradictions. [---] ... question norms, practices and opinions; to reflect on own one's [sic] values, perceptions and actions; and to take a position in the sustainability discourse (UNESCO, 2017, p. 10).

Our tentative suggestion for a way of dealing with the challenge of incorporating the ethical dimension of sustainability in ESD-teaching is to 
abandon the theory-based approach to ethics education and turn to a particular methods-based alternative to it. There is not room within the scope of this paper to explain this methods-based approach to ethics education in any detail, so instead we direct the interested reader to our previous papers in which we have elaborated this approach (Samuelsson \& Lindström, 2017; Samuelsson \& Lindström, 2020). Here we will only briefly sketch it in relation to ESD.

The methods-based approach proceeds from acknowledging certain methods for moral reasoning, which can be assembled under the headings information, vividness and coherence. These methods should be considered uncontroversial in the sense that they can be agreed upon irrespective of one's view on which ethical theory (if any) that is correct, and almost irrespective of one's views on the nature of morality. Together they can provide the basis for fruitful practical ethics education.

Very roughly, using these methods amounts to (1) collecting as much relevant correct information as possible, and getting rid of false beliefs; (2) representing this information as vividly as possible (that is, among other things, in a way where one grasps the circumstances of others - how it is to be them in the situation they are in - and appreciates the full significance, for all involved, of the different decisions one could make in a certain situation or regarding a certain issue); and (3) reasoning coherently on the basis of one's vividly represented information (involving, among other things, avoiding logical inconsistencies, avoiding confused concepts, and respecting the requirement of universalizability) (see, e.g., Samuelsson \& Lindström, 2020).

Let us end this section by listing what we take to be the main advantages of using the methods-based approach to ethics education in the context of ESD:

It does not take any particular ethical theory or perspective as a point of departure (it is neutral between ethical theories). This also means that no ethical perspective is excluded in advance - and it is an open question which information that is relevant for dealing with a certain problem. Thus, it fits neatly within the democratic, participatory framework of ESD (see further, Samuelsson \& Rist, 2016), where the pupils or students take part in forming their own understanding of sustainable development - its content, the ethical and political challenges that it brings to the fore, and promising ways forward. Consequently, the methods-based approach answers the first part of the challenge that we posed above, that the approach to ethics education in ESD should be "(1) suitable with respect to both its content and its educational procedure".

Moreover, the methods-based approach does not require the teacher to be well-versed in ethical theory. The methods are fairly easy to learn and practice, and they do not require a philosophical background. Thus, it answers the second part of the challenge that we posed above, that the approach to ethics education in ESD should be" (2) available also to teachers who are not experienced within the field of ethics".

Lastly, the methods can be introduced successively, where different methods - or aspects of them - are suitable for different target groups, e.g., for pupils of different ages. While information and its importance may be easy to grasp, some aspects of coherence are much more complicated. Even small children can 
arguably begin to work with information and vividness, whereas high school pupils can grasp the role and importance of various aspects of coherence.

\section{Conclusion}

In this paper we have provided an account of the ethical dimension of education for sustainable development (ESD). The importance and multifaceted complexity of this dimension show that ethical considerations should have a central place in ESD. But we have also argued that these ethical considerations provide challenges for ESD-teachers. However, as revealed by the discussion in the previous section, we are optimistic as to the prospects of overcoming these challenges. We believe that there is at least one approach to ethics education - the methods-based approach - that meets the following two requirements:

(1) It allows teachers to work with the various ethical aspects of sustainability by way of the kind of democratic participatory educational procedure inherent in the concept of ESD; (2) it is accessible also to teachers who are not well-versed in ethical theory.

Against the background of these conclusions, we end this paper by encouraging teachers involved in ESD to incorporate the ethical dimension of sustainable development in their teaching, not as a one-off event, but as an aspect that permeates the education and is continuously and actively discussed with the aid of the methods for moral reasoning.

\section{Acknowledgments}

This paper was written as part of the project "Future People and the Concept of Sustainability" (registration number: 2016-01535), funded by FORMAS.

\section{References}

Beckerman, W. (1994). 'Sustainable Development': Is it a Useful Concept? Environmental Values, 3(3), 191-209.

Brock, G., \& Miller, D. (2019). Needs in Moral and Political Philosophy. In E. N. Zalta (ed.), The Stanford Encyclopedia of Philosophy. Summer 2019 Edition.

Davis, M. (2011). The Usefulness of Moral Theory in Teaching Practical Ethics: A Reply to Gert and Harris. Teaching Ethics, 12(1), 51-60.

Davis, M. (2014). Professional Ethics without Moral Theory: A Practical Guide for the Perplexed Non-Philosopher. Journal of Applied Ethics and Philosophy, 6(1), 1-9.

Dobson, A. (1998). Justice and the Environment: Conceptions of Environmental Sustainability and Theories of Distributive Justice. Oxford: Oxford University Press.

Du Pisini, J. A. (2006). Sustainable Development - Historical Roots of the Concept. Environmental Sciences 3(2), 83-96.

Franck, O., \& Osbeck, C. (Eds.) (2017). Ethical Literacies and Education for Sustainable Development: Young People, Subjectivity and Democratic Participation. London: Palgrave Macmillan.

Hand, M. (2018). A Theory of Moral Education. London: Routledge. 
Hickel, J., \& Kallis, G. (2019). Is Green Growth Possible? New Political Economy, 25(4), 469-486.

Jacobs, M. (1999). Sustainable Development as a Contested Concept. In A. Dobson (ed.), Fairness and Futurity: Essays on Environmental Sustainability and Social Justice, 21-45. Oxford: Oxford University Press.

Leist, A., \& Holland, A. (2000). Conceptualising Sustainability. In Environmental Valuation in Europe Policy Research Brief, 5. Cambridge: Cambridge Research for the Environment.

Lélé, S. M. (1991). Sustainable Development: A Critical Review. World Development, 19(6), 607-621.

Meyer, L. (2016). Intergenerational Justice. In E. N. Zalta (ed.), The Stanford Encyclopedia of Philosophy. Summer 2016 Edition.

O’Neill, J. (2001). Sustainability: Ethics, Politics and the Environment. In J. O’Neill, R. K. Turner, \& I. Bateman (eds.), Environmental United Nations. Cheltenham: Edward Elgar Publishing Ltd.

Öhman, J. (Ed.) (2008). Values and Democracy in Education for Sustainable Development - Contributions from Swedish Research. Malmö: Liber.

Oulton C., Day, V., Dillon, J., \& Grace, M. (2004). Controversial Issues - Teachers' Attitudes and Practices in the Context of Citizenship Education. Oxford Review of Education, 30(4), 489-507.

Parrique T., Barth, J., Briens, F., Kerschner C., Kraus-Polk, A., Kuokkanen, A., et al. (2019). Decoupling Debunked: Evidence and Arguments against Green Growth as a Sole Strategy for Sustainability. European Environmental Bureau.

Samuelsson, L,. \& Lindström, N. (2017). Teaching Ethics to Non-Philosophy Students - A Methods-Based Approach. ATINER's Conference Paper Series, No: EDU2017-2338, $1-17$.

Samuelsson, L., \& Lindström, N. (2020). On the Practical Goal of Ethics Education: Ethical Competence as the Ability to Master Methods for Moral Reasoning. Teaching Philosophy, 43(2), 157-178.

Samuelsson, L., \& Rist, L. (2016). Stakeholder Participation as a Means to Produce Morally Justified Environmental Decisions. Ethics, Policy \& Environment, 19(1), 7690.

Stradling, R. (1985). Controversial Issues in the Curriculum. Bulletin of Environmental Education, 170(Jul), 9-13.

UNESCO (2017). Education for Sustainable Development Goals: Learning Objectives. Paris: UNESCO.

UNESCO (2019a). Education for Sustainable Development: Partners in Action - Global Action Programme (GAP) Key Partners' Report (2015-2018). UNESCO.

UNESCO (2019b). What is Education for Sustainable Development? UNESCO.

United Nations (2019). Sustainable Development Goal 4. Retrieved from: https://sustai nabledevelopment.un.org/sdg4. [Accessed 16 April 2020.]

Van Poeck, K., Östman, L., \& Öhman, J. (Eds.) (2019). Sustainable Development Teaching: Ethical and Political Challenges. London: Routledge.

World Commission on Environment and Development (1987). Our Common Future. Retrieved from: https://sustainabledevelopment.un.org/content/documents/5987ourcommon-future.pdf. [Accessed 16 April 2020.] 